\title{
Dossier Metodologías participativas alternativas o contrahegemónicas: otros modos de vivir, hacer y conocer
}

\author{
Carola Mick, ${ }^{1}$ Natalia Bisio, ${ }^{2}$ Mina Kleiche-Dray ${ }^{3}$ y Mercedes Oraisón ${ }^{4}$ \\ http://dx.doi.org/10.30972/dpd.10154805
}

\section{Introducción}

En 1960 y 1970, en el contexto de las teorías de la liberación y el pensamiento crítico latinoamericano, surgen diversas propuestas de hacer ciencia y construir conocimiento, alternativas a las formas hegemónicas, que se fueron consolidando como una contracorriente a las explicaciones dominantes de los procesos económicos y sociales. Bajo el lema acuñado por Fals Borda: "O ciencia rebelde, nueva, constructiva, o ciencia de segunda clase, imitativa y desadaptada", Ixs investigadorxs comprometidxs con el cambio social buscaron producir conocimiento práctico y socialmente útil, al margen de los temas impuestos por las agencias de ciencia y tecnología. Se planteó un acercamiento a la cultura y los conocimientos populares y se incorporó a Ixs actorxs sociales como co-responsables de los procesos de investigación. El efecto que se quería producir era la toma de conciencia y la reflexión crítica sobre las relaciones de dominación y dependencia que involucraban tanto a Ixs actorxs sociales como a Ixs académicxs.

La metodología de la investigación acción participativa (IAP) emerge en este escenario, propiciando un mayor involucramiento de Ixs propixs protagonistas en la búsqueda y el análisis de información y en la generación de soluciones. La IAP fue considerada una estrategia fundamental para que los sectores subordinados puedan visibilizarse, hacer oír su voz y promover transformaciones sociales y políticas. Sin embargo, estas perspectivas políticas, teóricas y metodológicas fueron resistidas y menospreciadas por los grupos más conservadores y canónicos que las cuestionaron por asumir que se trataban de abordajes con insuficiente rigor científico.

Actualmente asistimos a un auge del enfoque participativo en muchos ámbitos de la sociedad, particularmente en el de la política, el arte y la pedagogía, pero también en el de

\footnotetext{
1 - Centre Population et Développement (Ceped), Université de Paris \& Institut de recherche pour le développement (IRD), París, Francia.

${ }^{2}$ Departamento de Ciencias Sociales del Centro Universitario Regional Litoral Norte de la Universidad de la República del Uruguay.

${ }^{3}$ Centre Population et Développement (Ceped), Institut de recherche pour le développement (IRD) \& Université de Paris, París, Francia.

${ }^{4}$ Centro de Estudios Sociales/Facultad de Humanidades de la Universidad Nacional del Nordeste.
} 
las ciencias y de las tecnologías. Las ciencias sociales se han ido apropiando de estas metodologías para desarrollar investigaciones que permitan conectar intereses, preocupaciones y recursos, alentado alianzas entre la Universidad y Ixs actorxs territoriales. Así, en parte del mundo académico se ha ido consolidando un conjunto de posiciones caracterizadas como "participativas", provenientes de distintas geografías, encuadres teóricos, disciplinas e intereses que, sin llegar a constituirse en un cuerpo homogéneo y coherente, se orientan a descubrir alternativas a los estilos, a las prácticas y a los discursos de la modernidad y su modelo de producción de saberes y subjetividades.

Sin embargo, es posible advertir que las motivaciones, las racionalidades y las consecuencias de la participación son muy diversas; de hecho, mientras muchas formas de participación, bajo el lema de la "extensión universitaria" o la "responsabilidad social universitaria", sirven de simple mecanismo de justificación de modos académicos hegemónicos de conocer e investigar, otras buscan la deconstrucción y revisión crítica de las culturas y las estructuras institucionales vigentes.

El presente dossier considera, siguiendo a Lander (2000), que las ciencias sociales pierden su potencial crítico emancipador al continuar legitimando saberes, prácticas y discursos que contribuyen a ocultar, negar, subordinar o extirpar toda experiencia o expresión cultural que no se ha correspondido con el patrón de superioridad de la modernización, la civilización y la superioridad del hombre blanco.

Como recuerda la teoría decolonial, la constitución histórica de las disciplinas científicas que se produce en la academia occidental es una construcción eurocéntrica, que piensa y organiza a la totalidad del tiempo y del espacio, y a toda la humanidad, a partir de su propia experiencia, colocando su especificidad histórico-cultural como punto de referencia universal.

Este dispositivo de conocimiento colonial se instala como la forma "normal" del ser humano y de la sociedad. Las otras formas de ser, las otras formas de organización de la sociedad, las otras formas del saber, son consideradas diferentes, carentes, arcaicas, primitivas, tradicionales, premodernas. Dentro del imaginario del progreso se enfatiza su inferioridad (Cortes, 2014).

Con la intencionalidad de romper con esta epistemología que polariza, jerarquiza, subordina y excluye, este dossier se propone recuperar otros modos de ver, de hacer y de vivir, presentando una selección de trabajos de investigación realizados por académicxs universitarixs, en colaboración con actorxs sociales, cuyos marcos de referencia proponen la reinvención, no solamente de metodologías de estudio, sino también de formas de observar, analizar, poder, saber, ser y vivir que logren emanciparse de posicionamientos modernos, eurocéntricos y desarrollistas. 
Los trabajos que se despliegan en el dossier, se agrupan en diversos ejes que dan cuenta del surgimiento de nuevos diálogos entre la academia y el saber popular, así como de nuevas dimensiones desde las cuales mirar y nombrar el devenir de la realidad social.

Uno de los ejes que aglutina un conjunto de artículos se centra en la educación, en la educación sistemática y formal. Lxs autorxs de estos escritos parten de reconocer a la educación, junto con la ciencia, como uno de los dispositivos por excelencia de colonialización, pero al mismo tiempo asumen que es necesario trabajar desde adentro, desde los espacios académicos y escolares para poder plantear reconfiguraciones, generar transformación y pensar alternidades.

Tales artículos presentan prácticas innovadoras, rupturistas y transformadoras y coinciden en la necesidad de descubrir, diseñar e implementar otras formas de producir y socializar el conocimiento, que involucren los saberes históricamente marginados de la educación hegemónica. En ellos se relatan experiencias promovidas desde el campo institucional que intentan encontrar "resquicios" para convocar a otras voces, otras culturas, otros valores creando lo que Zulma Palermo llama "espacios pluriversos". Las experiencias narradas revalorizan el protagonismo de Ixs actorxs no académicxs, la conexión con el territorio, el conocimiento situado, el diálogo como estrategia pedagógica fundamental y la diversidad y pluralidad de voces y perspectivas.

Así, Zulma Palermo en Haceres de saberes disruptivos: las comunalidades creativas nos desafía a pensar en un hacer pedagógico descolonizante a partir de su propuesta de "las comunalidades creativas" que acogen a colectivos culturales, sociales y políticos en la búsqueda disruptiva de haceres y pensares contraletrados y contraacadémicos. Entiende que las prácticas que tienen en sí mismas un valor pedagógico disruptivo son aquellas que se orientan a darnos re-existencia como sociedades aún hoy colonizadas, mediante un conocimiento colectivamente producido que permee las distintas formas de producción social. Por ello, estas prácticas pueden ser epistémicas, económicas, artísticas o educativas. Lo que esta autora nos ofrece en el artículo es una síntesis de relatos de las experiencias que se concretaron en diferentes escenarios de creatividad en interacción, que no pretenden ser un recetario metodológico, sino la evidencia de que es posible pensar y construir "un mundo en el que quepan muchos mundos".

Denise Zenklusen y Mauricio Menardi, en Apuntes para pensar la articulación entre desarrollo territorial y educación a partir de la experiencia de una cátedra universitaria, analizan la relevancia de las herramientas de la Investigación-Acción-Participativa y del Aprendizaje Servicio en un proceso de co-generación de conocimientos en el que el territorio no es considerado destinatario, sino actor central, punto de partida y de llegada. El trabajo comparte la sistematización de una experiencia de cátedra que da la posibilidad a Ixs estudiantxs de asumir un rol activo en sus aprendizajes, comprometiéndolos en la 
construcción democrática de su entorno, configurando las aulas como espacios de cambio social en articulación con los territorios.

Lucía Elena Rodríguez McKeon, Adalberto Rangel Ruiz de la Peña y Nelly del Pilar Cervera Cobos, en Crítica y participación en la alquimia de la investigación-acción. Una experiencia de formación en convivencia, presentan otra experiencia participativa e innovadora desde dentro del sistema y las instituciones educativas orientada a la construcción de formas de mejoramiento de la convivencia en las escuelas. El artículo analiza los aportes de la investigación acción en la construcción de propuestas alternativas para afrontar los conflictos que permiten trascender lo curricular para dejar ver lo ético-político, propiciando relaciones pedagógicas más horizontales.

Vinculado al eje anterior, pero profundizando en la generación de propuestas alternativas, comunitarias y colectivas para la satisfacción de necesidades de diversas poblaciones, otro núcleo de artículos nos propone pensar la potencialidad de la educación popular, el arte, la participación comunitaria y la investigación militante. El esfuerzo está puesto en la identificación de las prácticas cotidianas colonizadas por modos de ser y de hacer que han anulado la riqueza del saber popular. Saber que recupera su centralidad a la hora de hacerse cuerpo en las distintas formas de resistencia y de emancipación que las comunidades van construyendo.

El artículo de Colin Huizar, La práctica etnográfica desde el compromiso social. Aprendizajes de la colaboración con docentes sindicalistas de Michoacán, México, relata una experiencia de investigación etnográfica comprometida. Reconstruye una larga historia de colaboración con un movimiento magisterial en México que busca influenciar en las políticas educativas mediante una toma de conciencia del privilegio académico y la creación de relaciones horizontales con las familias. Desde herramientas dialógicas de inter-aprendizaje, explora y valoriza los espacios de encuentro dentro de la academia desde los cuales se transforma, no solamente a nivel de los discursos, sino también la práctica tanto educativa como de investigación.

En La ventana infinita. Método de educación no formal, resiliencia y participación comunitaria, Teresa Lobo y Teresa Yurén nos plantean que para transformar el mundo hay que problematizarlo en un diálogo horizontal de saberes entre educandx y educadorx, recuperando en dicho acto el sentido de la práctica como praxis histórica y culturalmente situada. Este proceso, política y éticamente orientado, permite al ser humano tomar conciencia de sus condiciones de vida y de sus capacidades para transformarlas. Desde esta perspectiva, presentan la experiencia desarrollada con poblaciones en situación de vulnerabilidad y otras que viven en contextos rurales dispersos, con el fin de dignificar su vida mediante la creación artística como disparador del proceso educativo y motor para 
identificar sus necesidades y sus dolores y transformarlos en potencia creadora en y desde la acción colectiva de las comunidades.

Por su parte, Cejas y Mandrini, en Saberes in-corporados. Enfoques contrahegemónicos para la producción del hábitat, analizan las tensiones, contradicciones y aprendizajes que fueron emergiendo en el proceso de construcción colaborativa de cocinas comunitarias, descubriendo, en ello, nuevas formas de acercarnos al conocimiento mediante el diálogo entre los cuerpos que hablan y reflejan sus formas de ser y conocer en el hacer. La palabra como forma impuesta de ordenar y conocer el mundo que habitamos no es la única válida; reconocer la incompletitud del saber, en palabras de Boaventura de Sousa Santos, implica, entre otros, cambiar la espacialidad hegemónicamente fijada del acto de conocer. La experiencia que comparten las autoras propone, en este sentido, una metodología de trabajo con las comunidades para la producción colectiva y contra-hegemónica del hábitat.

Finalmente, en Que tenga un pequeño jardín de flores. Una experiencia participativa entorno al turismo y el patrimonio cultural en el Impenetrable chaqueño, redactado por Gabriela Barrios et al., y en Contextos adversos para la participación: intercambio y consumo de drogas. Resistencias en barrios populares del Gran San Miguel de Tucumán, Argentina, de Débora Decima y Paula Boldrini, las autoras reivindican el aporte de las metodologías participativas en la generación de conocimiento para la transformación de realidades cotidianas atravesadas por múltiples expresiones de sufrimiento comunitario, pero también de esperanza y luchas por superarlo. En el primer caso, se trata de una experiencia de desarrollo turístico en proceso, en el cual se propone la recuperación de la memoria y la cultura de las comunidades lugareñas mediante la reconstrucción de la antigua escuela, tensionada por los mandatos institucionales de organismos internacionales donde la participación aparece como un instrumento más de control que de emancipación. Además de los conflictos generados en torno al uso de la tierra, emergen en dicho proceso otros vinculados a la historia de discriminación y visibilización que padecieron los pueblos originarios y que hoy día se reactualizan en otros escenarios y con otrxs actorxs. En el segundo, se abordan las situaciones de vulnerabilidad que viven las familias y jóvenes afectados por la venta y el consumo de drogas, promoviendo salud a partir del trabajo colectivo en torno a los emergentes sociales identificados y problematizados por la propia comunidad. En este marco, las autoras destacan las transformaciones generadas en la comunidad en términos individuales-terapéuticos para los jóvenes involucrados activamente en el proceso, y colectivos en la resignificación del hábitat y su barrio. Finalmente, cabe destacar que, no obstante, la reivindicación de la validez de visibilización más allá de las fronteras y los estigmas construidos en torno a los procesos vivenciados, los trabajos también dan cuenta de los obstáculos que desde las distintas esferas del poder hegemónico 
se comienzan a desplegar cuando esas comunidades, esas poblaciones silenciadas u oprimidas empiezan a hacer valer su voz.

Un tercer grupo de trabajos recupera distintas experiencias y reflexiones vinculadas a proyectos participativos de desarrollo territorial. En el artículo Teoría y práctica de las metodologías participativas. Análisis de su utilización para la elaboración de agendas de desarrollo territorial en Uruguay, Mariano Suárez revisa, desde una posición epistémica del pensamiento complejo, una experiencia de participación ciudadana en la construcción de Agendas del Desarrollo Territorial, en la construcción de política de descentralización del poder del gobierno central a los gobiernos municipales. Se cuestionan las condiciones de posibilidad de llevar a cabo una gobernanza multinivel para el desarrollo territorial. Movilizando herramientas tradicionales de participación ciudadana, las interacciones entre actorxs representantes de instituciones a diferentes niveles del gobierno, Ixs miembrxs del equipo técnico y Ixs actorxs locales, efectivamente, logran visibilizar la complejidad que enfrentan en la construcción colectiva de diálogos multi-actorxs en las agendas locales. Esto rompe con un monólogo centralista estatal y le devuelve autoridad a Ixs actorxs en materia de planificación del desarrollo del territorio que habitan. Problematiza, sin embargo, la heterogeneidad de las temporalidades institucionales y territoriales, la diversidad de los conocimientos más allá del conocimiento experto, los intereses políticos de Ixs actorxs, así como las estrategias para convocarlxs y motivarlxs a comprometerse con un proceso de índole administrativo. La perspectiva de la complejidad ha permitido al autor afirmar la necesidad de una gobernanza integral para dar cuenta de la realidad dentro de la que se está involucradx.

El artículo Cartografiar lo común: trabajo colaborativo e interdisciplinar para la resemantización territorial enfoca la cartografía social, un método clave de la IAP como productora de la realidad social/del mundo/de territorio por sus habitantes y del fortalecimiento de la identidad colectiva. El objetivo es el de visibilizar un conjunto de aspectos constitutivos de sus territorios como los bienes comunes y la diversidad económica, así como la forma de gobernanza de las comunidades para dar visibilidad a otras inscripciones de procesos económicos invisibilizados por la hegemonía estatal y capitalista.

A partir de ejercicios de diseño colaborativo y diálogo de saberes entre varias comunidades campesinas e indígenas del centro-sur de Chile y el mundo académico, se intentó elaborar un diagnóstico co-construido. Los autores, después de dar una definición de la cartografía social como instrumento de la IAP, presentan las diferentes etapas de la metodología de elaboración de la cartografía participativa y luego cómo se ha hecho el diseño conjunto de los mapas en el estudio de caso que incluyeron elementos relevantes y referenciales del territorio desde la perspectiva de la comunidad: identificación e historidad de los comunes, tragedias y despojos del común, gobernanza del común (defensa, cuidado y 
reglas de acceso, de uso, de promoción y expansión/preservación, ampliación, fortalecimiento del común) para entender las normas, los límites, los proyectos, acciones, actores clave en torno a los comunes. Se finaliza el mapeo con la sistematización de los datos, resemantizando la realidad, de las problemáticas y posibilidades de proyección política hacia el futuro.

Más allá del estudio de caso, los autores pretenden construir una plataforma de reflexión colectiva sobre este proceso que califican de transculturalidad y transvalorización en la medida que transforma a los actores involucrados y las relaciones entre academiacomunidad. Es importante destacar el hecho de que cuando se habla de mapear con material espacial y simbólico de todos los actores involucrados, se trata de aprendizaje y desafío mutuo que se convierte en algún común.

La cuestión del territorio es también clave dentro las actividades de otro instrumento de acción participativa: los observatorios de conflictos sociales. El artículo Estrategias y desafíos en extensión universitaria: la experiencia del Observatorio de Conflictos Sociales del Nordeste Argentino (OCSo-NEA), escrito por Fernando Nahuel Marturet et al., nos hace el relato reflexivo de las acciones que se han llevado a cabo desde 2017 - que Ixs autorxs Ilaman a la memoria- a partir de esta iniciativa de académicos asociados hacia asociaciones sociales, territoriales, políticas, básicamente sobre tres temas -Género y diversidades, Ambiente y territorio, y Derechos Humanos- en varias provincias del norte de la Argentina.

En el artículo se analizan las estrategias y las acciones de lxs actorxs involucradxs en el observatorio para co-producir conocimiento junto con y para las organizaciones sociales, relacionado al tema de las violencias sociales y estatales que sea por Ixs agentes policiales y penitenciarios, que sea sobre el feminicido y travesticidos, los impactos de los agrotóxicos que, además, se relacionan por estos últimos al acceso de bienes comunes y espacios de vida.

El artículo describe la metodología de trabajo usada y da cuenta de las acciones y estrategias que ha desarrollado el equipo para denunciar estas violencias construyendo registros de un lado, pero también reflexionando sobre las categorías adecuadas para nombrar a las víctimas como en el caso de la población que no entre en las categorías clásicas de género hombre/mujer. Se subraya la importancia de tejar redes con otros observatorios de otras provincias para ampliar los registros e intercambiar experiencias para superar los obstáculos de invisibilidad que tocan a las víctimas.

Asimismo, se hizo al interior del equipo de académicxs una reflexión crítica sobre este conocimiento de extensión co-producido: ¿Qué significa producir conocimiento dentro el marco de una asociación social cuyo objetivo es el de construir herramientas para solucionar 
problemas? Lo que muestra este artículo es que luchar contra las violencias denunciándolas contribuye a posibilitar acciones judiciales.

El dossier logra aportar distintas reflexiones, sistematizaciones y relatos sobre experiencias locales/territoriales concretas que responden a estos "otros" enfoques; escritos que dan cuenta de la multiplicidad de voces y de mundos de vida que coexisten en nuestra región; trabajos que reflejan otros modos de conocer y de hacer investigación, otras lógicas y racionalidades que ponen en diálogo saberes y subjetividades diversos. Esperamos que la lectura de los artículos que compartimos en este dossier nos invite a resignificar la dimensión política y transformadora del conocimiento.

\section{Bibliografía}

Cortés, A. (2014). Antropología, desarrollo e interculturalidad: Propuestas desde América Latina. Revista de Antropología Social, 23, 9-28.

Lander, E. (2000). La colonialidad del saber: eurocentrismo y ciencias sociales. Perspectivas Latinoamericanas. Buenos Aires: Clacso. 